\title{
Genomic epidemiology reveals geographical clustering of multidrug-resistant Escherichia coli sequence type (ST)131 associated with bacteraemia in Wales, United Kingdom
}

\subsection{Author names}

Rhys T. White ${ }^{1,2}$ https://orcid.org/0000-0001-6620-758X, Matthew J. Bull,4 https://orcid.org/0000-0002-8701-0417, Clare R. Barker ${ }^{3}$ http://orcid.org/0000-0002-32765628, Julie M. Arnott ${ }^{5}$, Mandy Wootton ${ }^{4}$ https://orcid.org/0000-0002-2227-3355, Lim S. Jones $^{4}$, Robin A. Howe ${ }^{4}$, Mari Morgan ${ }^{5}$, Melinda M. Ashcroft ${ }^{6}$ https://orcid.org/0000-00019157-4533, Brian M. Forde ${ }^{7}$ https://orcid.org/0000-0002-2264-4785, Thomas R. Connor ${ }^{3 *}$ https://orcid.org/0000-0003-2394-6504, Scott A. Beatson ${ }^{1,2^{*}}$ https://orcid.org/0000-00021806-3283

\subsection{Affiliation}

${ }^{1}$ School of Chemistry and Molecular Biosciences and Australian Infectious Disease Research Centre, The University of Queensland, Brisbane, Queensland 4072, Australia

${ }^{2}$ Australian Centre for Ecogenomics, The University of Queensland, Brisbane, Queensland 4072, Australia

${ }^{3}$ Microbiomes, Microbes and Informatics Group, Organisms and Environment Division, School of Biosciences, Cardiff University, Cardiff, Wales CF10 3AX, United Kingdom

${ }^{4}$ Public Health Wales Microbiology, University Hospital Wales, Cardiff, Wales CF14 4XW, United Kingdom

${ }^{5}$ Healthcare Associated Infection, Antimicrobial Resistance \& Prescribing Programme (HARP), Public Health Wales, 2 Capital Quarter, Tyndall Street, Cardiff, Wales CF 10 4BZ, United Kingdom

${ }^{6}$ Department of Microbiology and Immunology, The University of Melbourne at The Peter Doherty Institute for Infection and Immunity, Melbourne, Victoria, Australia

${ }^{7}$ The University of Queensland, UQ Centre for Clinical Research (UQCCR) and Australian Infectious Disease Research Centre, Royal Brisbane \& Women's Hospital Campus, Herston, Queensland 4029, Australia

\subsection{Corresponding authors}

Thomas R. Connor;

Telephone: +44-29-20874147;

Email: connortr@cardiff.ac.uk

Scott A. Beatson;

Telephone: +61-7-33654863;

Email: s.beatson@uq.edu.au

\subsection{Keywords}

Escherichia coli; bacteraemia; ST131; whole-genome sequencing; genomics 
medRxiv preprint doi: https://doi.org/10.1101/2021.05.21.21257487; this version posted May 24, 2021. The copyright holder for this preprint (which was not certified by peer review) is the author/funder, who has granted medRxiv a license to display the preprint in perpetuity.

\subsection{Author notes}

All supporting data, code and protocols have been provided within the article or through supplementary data files. Supplementary methods and supplementary tables are available with the online version of this article.

\subsection{Abbreviations}

3GCs, third-generation cephalosporins; AMR, antimicrobial resistance; BWA, BurrowsWheeler Aligner; CA, common ancestor; catB, chloramphenicol-related O-acetyltransferase; CDS, coding sequence; CI, confidence interval; contigs, contiguous sequences; ECB, Escherichia coli bacteraemia; ESBLs, extended-spectrum $\beta$-lactamases; $f e b E$, ferric enterobactin transport protein; fryC, fructose-like permease IIC component; fum $C$, fumarate hydratase class II; GATK, Genome Analysis Tool Kit; HPD, highest posterior density; INDELS, insertions and deletions; IQR, interquartile range; IS, insertion sequences; MCC, maximum clade credibility; MCMC, Markov chain Monte Carlo; $m d h$, malate dehydrogenase; ML, maximum likelihood; MLST, multilocus sequence typing; NCBI, National Center for Biotechnology Information; NHS, National Health Service; NICE, National Institute for Clinical Excellence; PHW, Public Health Wales; RefSeq, Reference Sequence; SNPs, singlenucleotide polymorphisms; SACU, Specialist Antimicrobial Chemotherapy Unit; SRA, Sequence Read Archive; ST, sequence type; syn, synonymous; UK, United Kingdom; UPEC, Uropathogenic Escherichia coli; USA, United States of America; UTIs, urinary tract infections; WGS, whole-genome sequencing; XAT, xenobiotic acyltransferase.

\section{Abstract}

Increasing resistance to third-generation cephalosporins (3GCs) threatens public health, as these antimicrobials are prescribed as empirical therapies for systemic infections caused by Gram-negative bacteria. Resistance to 3GCs in urinary tract infections (UTIs) and bacteraemia is associated with the globally disseminated, multidrug-resistant, uropathogenic Escherichia coli sequence type (ST)131. This study combines the epidemiology of E.coli blood culture surveillance with whole-genome sequencing (WGS) to investigate ST131 associated with bacteraemia in Wales between 2013 and 2014. This population-based prospective genomic analysis investigated temporal, geographic, and genomic risk factors. To identify spatial clusters and lineage diversity, we contextualised 142 genomes collected from twenty hospitals, against a global ST131 population $(n=181)$. All three major ST131 clades are represented across Wales, with clade $\mathrm{C} / H 30$ predominant $(n=102 / 142,71.8 \%)$. Consistent with global findings, Welsh strains of clade $\mathrm{C} / H 30$ contain $\beta$-lactamase genes from the $b a_{\mathrm{CTX}-\mathrm{M}-1}$ group $(n=65 / 102,63.7 \%)$, which confers resistance to 3GCs. In Wales, the majority of clade $\mathrm{C} / H 30$ strains belonged to sub-clade $\mathrm{C} 2 / H 30 \mathrm{Rx}(n=88 / 151,58.3 \%)$, whereas sub-clade $\mathrm{C} 1 / H 30 \mathrm{R}$ strains were less common $(n=14 / 67,20.9 \%)$. A sub-lineage unique to Wales was identified within the C2/H30Rx sub-clade (named GB-WLS.C2/H30Rx) and is defined by six non- 
medRxiv preprint doi: https://doi.org/10.1101/2021.05.21.21257487; this version posted May 24, 2021. The copyright holder for this preprint

recombinogenic single-nucleotide polymorphisms (SNPs), including a missense variant in $f e b E$ (ferric enterobactin transport protein) and fry $C$ (fructose-like permease IIC component), and the loss of the capsular biosynthesis genes encoding the K5 antigen. Bayesian analysis predicted that GB-WLS.C2/H30Rx diverged from a common ancestor (CA) most closely related to a Canadian strain between 1998 and 1999. Further, our analysis suggests a descendent of GB-WLS.C2/H30Rx arrived through an introduction to North Wales circa 2002, spread and persists in the geographic region, causing a cluster of cases (CA emerged circa 2009) with a maximum pair-wise distance of 30 non-recombinogenic SNPs. This limited genomic diversity likely depicts local transmission within the community in North Wales. This investigation emphasises the value of genomic epidemiology, allowing detection of suspected transmission clusters and the spread of genetically similar/identical strains in local areas. These analyses will enable targeted and timely public health interventions.

\section{Impact statement}

Uropathogenic Escherichia coli (UPEC) is a leading cause of bacteraemia, resulting in substantial mortality and morbidity, with rates of E. coli bacteraemia (ECB) becoming a particular concern in Wales(1). Previous genomic and multilocus sequence typing (MLST) studies have identified that ECB cases are disproportionately caused by specific groups [sequence types $(\mathrm{ST})$ ] of related E. coli. Previous work reports ST131 as a globally disseminated lineage associated with bacteraemia and antimicrobial resistance (AMR). Despite widespread study of ECB, the temporal and geographic patterns of key ECB clones remain an important area of study. Moreover, by gaining a detailed understanding of the population structure of key ECB clones, it should be possible to develop and improve public health measures to reduce the risk of ECB and act to combat the rise of AMR. Using whole-genome sequencing, we describe the temporal and spatial relationship of a collection of E. coli ST131 bacteraemia cases sampled across Wales. High-resolution analyses of genetic variants identified a local (North Wales) cluster of strains within the highly antimicrobial-resistant subclade $\mathrm{C} 2 / H 30 \mathrm{Rx}$, which are characterised by resistance to nitrofurantoin and the loss of the K5 capsule. Notably, AMR stewardship guidelines in Wales recently changed to include nitrofurantoin as a first-line treatment for uncomplicated UTIs. This local cluster likely represents environmentally-mediated community transmission, environmentally mediated, from the strain's common ancestor that existed circa 2009, highlighting the need for national 
medRxiv preprint doi: https://doi.org/10.1101/2021.05.21.21257487; this version posted May 24, 2021. The copyright holder for this preprint (which was not certified by peer review) is the author/funder, who has granted medRxiv a license to display the preprint in perpetuity.

114 genomic surveillance, close to real-time, to track and understand the evolution of AMR in communities.

\section{Data summary}

118 The study sequences are available in the National Center for Biotechnology Information (NCBI) under BioProject accession number PRJNA729115. Raw Illumina sequence read data

120 have been deposited to the NCBI sequence read archive [SRA 121 (https://www.ncbi.nlm.nih.gov/sra)] under the accession numbers SRR14519411 to 122 SRR14519567. A complete list of SRA accession numbers is available in Table S1 (available 123 in the online version of this article). The high-quality draft assemblies have been deposited to 124 GenBank under the accession numbers JAHBGJ000000000 to JAHBMG000000000, and 125 JAHBRR000000000 to JAHBRT000000000. The programs used to analyse raw sequence 126 reads for polymorphism discovery and whole-genome sequencing based phylogenetic reconstruction are available as described in the materials and methods. The authors confirm all supporting data, code, and protocols have been provided within the article or through supplementary data files.

\section{Introduction}

132 Uropathogenic Escherichia coli (UPEC), bacteria causing infection rather than commensal 133 bacteria, are the leading cause of urinary and systemic infections. UPEC present an increasing 134 burden to public health due to increasing antimicrobial resistance (AMR). Increasing rates of 135 AMR can lead to treatment failures and progression to systemic bacteraemia infections. 136 Additionally, the emergence and dissemination of UPEC strains encoding AMR are causing economic damage to countries and healthcare systems(2). Incidences of $E$. coli associated bacteraemia are increasing globally. In Wales, the 5-year rolling average age-standardised mortality for deaths involving E. coli bacteraemia (ECB) almost doubled from 4.0 [95\% confidence interval (CI): 2.3 to 6.4] per 1 million population in 2002-06, to 7.7 (95\% CI: 5.4 to 10.6) in 2006-10 (Figure S1)(1). Previous studies have shown that most urinary tract infections (UTIs) are caused by a limited number of key UPEC clonal lineages including sequence types (ST)131, ST69, ST73, ST95 and ST12(3-5). UPEC are predominantly found within the E. coli phylogenetic groups B1, B2, or D. 
medRxiv preprint doi: https://doi.org/10.1101/2021.05.21.21257487; this version posted May 24, 2021. The copyright holder for this preprint

E. coli ST131 is a high-risk pandemic clone that is frequently associated with bacteraemia(6) and UTIs, and is a major circulating lineage in the United Kingdom (UK)(7). The successful transmission of ST131 globally is attributed to: (i) resistance to many treatments by the carriage of genes encoding resistance to multiple antimicrobial agents(8-10); (ii) the ability to cause disease that other opportunistic or commensal strains do not possess through pathogenicity, fitness, and metabolic factors(11-13); (iii) the ability to survive in human serum(14) due to capsule production(15); and (iv) transmission in various environments including healthcareand community-acquired transmission(16). ST131 can colonise and persist in hosts for extended periods causing recurrent UTIs, typically within 1-year of the initial infection(17). ST131 cases frequently harbour resistance to many broad-spectrum therapies such as thirdgeneration cephalosporins $(3 \mathrm{GCs})(18,19)$ and fluoroquinolones(20). In ST131, the carriage of extended-spectrum $\beta$-lactamases (ESBLs) facilitates the principal resistance mechanism to 3GCs.

In 2018, the UK National Institute for Clinical Excellence (NICE) issued guidelines concerning acute pyelonephritis(21). This recommended urine culture susceptibility testing and promoted the use of several $\beta$-lactams, trimethoprim, ciprofloxacin (fluoroquinolone), or amoxicillin and clavulanic acid as first-line antibiotics. This could be contributing to increasing rates of ESBLproducing E. coli across the UK(22). Between 2017-2018, data from England and Wales showed that at least $14.1 \%(n=4,950 / 35,050)(23)$ and $13.3 \%(n=354 / 2,663)(24)$ of $E$. coli bloodstream isolates presented resistance to $3 \mathrm{GCs}$, respectively. In England, this translates to approximately 5,000 annual cases, often due to ST131(4,7). Resistance to $\beta$-lactams like $3 \mathrm{GCs}$ can lead to increased usage of last-line therapies like carbapenems, with carbapenem resistance in UPEC also associated with ST131(25, 26). In 2017, rates of resistance to fluoroquinolones in ECB cases across Wales were as at least $20.3 \%(n=540 / 2,663)(24)$. NICE also promotes the use of nitrofurantoin or trimethoprim (first-line), and pivmecillinam or fosfomycin (secondline) antibiotics against lower UTIs(27). However, trimethoprim is no longer recommended in

173 Wales for the treatment of UTIs in the 65 and over age group(24). The increase in 174 antimicrobial-resistant infections is problematic on several levels. For example, patients are more likely to receive inappropriate empirical therapy involving an agent to which the pathogen is resistant. The circulation of strains with extensive levels of resistance to key antimicrobials, such as $3 \mathrm{GCs}$, increases the likelihood of UTI treatment failures, prolonging the length of

178 infection, potentially allowing the bacteria to flourish by removing commensal bacteria which 
medRxiv preprint doi: https://doi.org/10.1101/2021.05.21.21257487; this version posted May 24, 2021. The copyright holder for this preprint (which was not certified by peer review) is the author/funder, who has granted medRxiv a license to display the preprint in perpetuity.

compete for bacterial growth, and increases severe outcomes such as the risk of a patient developing bacteraemia, resulting in increased morbidity and mortality.

Genomic epidemiology, the use of whole-genome sequencing (WGS) in epidemiological investigations, is increasing worldwide in public health responses. With increasing rates of antimicrobial-resistant ECB, it is vital to understand the genetic relatedness of circulating strains on a local, national, and global scale. This work investigated the evolution of ST131 strains from patients in Wales with bacteraemia identified over a 12-month period. Genomic sequence data enabled the characterisation of circulating ST131 in Wales, showing multiple introductions of this global clone with localised or national transmission. Our analyses also reveal multiple bacteraemia cases caused by a unique geographically-restricted, monophyletic subgroup of ST131 within North Wales characterised by ESBL-production.

\section{Methods}

\subsection{Welsh $E$. coli isolate collection and genome sequencing}

Public Health Wales (PHW) laboratories were asked to submit all E. coli blood isolates from blood samples collected between April 2013 and March 2014, to the national Specialist Antimicrobial Chemotherapy Unit (SACU) at University Hospital Wales. The isolate dataset was linked to routine microbiological surveillance data by PHW to obtain isolate AMR profiles. Novel AMR profiles and profiles with phylo-geography were characterised by polymerase chain reaction. Selected samples were sequenced based on their determined phylogenetic groups. Isolates were transported to Cardiff University, cultured overnight in liquid culture, and extracted using a Promega (Wisconsin, USA) Maxwell instrument. Samples were sequenced as paired-end reads on either the NextSeq 500 or HiSeq 2500 platform (Illumina Inc, San Diego, CA, USA) at the Oxford Genomics Centre (https://www.well.ox.ac.uk/ogc/) or MicrobesNG (https://microbesng.com/). DNA libraries were prepared using a mixture of the Nextera $X T \AA$ Library Preparation Kit and the NEBNext ${ }^{\circledR}$ Ultra $^{\mathrm{TM}}$ Library Preparation Kit (Illumina Inc, San Diego, CA, USA), following the manufacturer's instructions in both cases.

This genomic surveillance of ECB in Wales collected 157 non-duplicate clinical E. coli ST131 strains as part of routine microbiological surveillance data from hospitals across six administrative units known as health boards (Figure S2). Patient anonymity was maintained by 
medRxiv preprint doi: https://doi.org/10.1101/2021.05.21.21257487; this version posted May 24, 2021. The copyright holder for this preprint (which was not certified by peer review) is the author/funder, who has granted medRxiv a license to display the preprint in perpetuity.

212 pseudonymised data that went outside PHW. Epidemiological information, including isolate 213 names and available metadata are summarised in Supplementary Tables S1 and S2. The WGS

214 of the $157 \mathrm{E}$. coli isolates generated a median of 0.89 million paired-end reads per sample 215 [interquartile range (IQR): 0.43 to 1.09 million; range: 0.14 to 3.37 million] (Table S2).

216 Sequence read data for all Welsh isolates were submitted to the National Center for 217 Biotechnology Information Sequence Read Archive under BioProject accession number 218 PRJNA729115. The methods used for quality control for this dataset are available in the 219 Supplementary Methods. Briefly, we identified and excluded the sequence data for 15 isolates from further analysis based on the sequencing coverage below 20-fold (Table S3).

\subsection{Draft genome assembly}

Quality-trimmed paired-end reads for the remaining 142 Welsh strains were de novo assembled using MGAP (https://github.com/dsarov/MGAP---Microbial-Genome-Assembler(https:/github.com/tseemann/VelvetOptimiser); GapFiller v1.10(29); ABACAS v1.3.1(30) [scaffolds against the chromosome of E. coli ST131 strain EC958 (GenBank: HG941718)]; IMAGE v2.4(31); SSPACE v2.0(32); Pilon v1.22(33); and MIRA v4(34). Contigs from the draft assemblies were ordered against the complete chromosome of EC958 using Mauve version snapshot_2015-02-25(35). QUAST v4.5(36) assessed the assembly statistics generated from MGAP by comparing each isolate to EC958 (Table S4).

\subsection{Complementary datasets}

To facilitate the geographic analysis of the 142 Welsh ST131 isolates within the global context, available isolate datasets were downloaded including: (i) sequence read data from the NCBI sequence read archive (SRA); (ii) draft assemblies; and (iii) associated metadata from Ben Zakour et al.(10) (n=189) and Kidsley et al.(37) ( $n=19)$. Notably, six draft assemblies from the Ben Zakour et al. study were replaced with the complete chromosomes: CD306 Methods. 
medRxiv preprint doi: https://doi.org/10.1101/2021.05.21.21257487; this version posted May 24, 2021. The copyright holder for this preprint (which was not certified by peer review) is the author/funder, who has granted medRxiv a license to display the preprint in perpetuity.

\subsection{Compiling a high-quality ST131 clade C/H30 global dataset}

For context, the Welsh clade $\mathrm{C} / H 30$ strains $(n=102)$ were inputted against a global collection of clade C/H30 ST131 strains $(n=117)$ from three published studies $(9,10,38)$ as featured in Kidsley et al.(37). Several complete genomes were integrated by simulating error free reads using ART (version ART-MountRainier-2016-06-05)(39) to 60x coverage with an insert size of $340 \pm 40$ bp. These included known clade C/H30 ST131 genomes: $2 / 0$ (GenBank: CP023853); 4/0 (GenBank: CP023849); 4/4 (GenBank: CP023826); 4/1-1 (GenBank: CP023844); MNCRE44 (GenBank: CP010876); U12A (GenBank: CP035476); U13A (GenBank: CP035477); U14A (GenBank: CP035516); U15A (GenBank: CP035720); and uk_P46212 (GenBank: CP013658). For this investigation, clade C/H30 strains JJ2183 (SRA: SRS456889), MVAST0036 (SRA: SRS456851), MVAST046 (SRA: SRS456881), and MVAST077 (SRA: SRS456882) were removed from the dataset based on the average sequence coverage depth below 20 -fold.

\subsection{Identifying genetic variants}

High-resolution analyses of genetic variants was performed using the BurrowsWheeler Aligner v0.7.15(40); SAMtools v1.2(41); Picard v2.7.1 (https://github.com/broadinstitute/picard); the Genome Analysis Tool Kit v3.2-2 (GATK)(42, 43); BEDTools v2.18.2(44); and SNPEff v4.1(45) as implemented in SPANDx v3.2(46). In brief, the trimmed reads were mapped to the complete chromosome of EC958; which was isolated in March 2005 in the United Kingdom from a community-onset urine infection in an 8year-old girl(11). When analysing the Illumina reads, 20 clade $\mathrm{C} / \mathrm{H} 30$ genomes from Price et al.(38) were excluded from this example dataset due to erroneous Phred quality encoding (Table S6). Our final dataset consisted of 226 genomes representing previously published datasets ( $n=124$, including 16 complete genomes) and our Welsh collection $(n=102)$ (Table S7).

\subsection{High-resolution phylogeny of the clade C/H30 ST131 sub-lineage}

The 226 strains [EC958 reference $(n=1)$ and dataset $(n=225)]$ were assessed for the presence of strain mixtures (see Supplementary Methods). Briefly, this approach readily flagged seven strains as a probable mixture based on the high number of ambiguous singlenucleotide polymorphisms (SNPs) (from a total of 7,592 SNPs) compared with the remaining 219 genomes [Median $51(0.7 \%)$; IQR 28 to 102 (0.4 to 1.3\%); range 2 to $171(0.0$ to $2.3 \%)$ ]. 
medRxiv preprint doi: https://doi.org/10.1101/2021.05.21.21257487; this version posted May 24, 2021. The copyright holder for this preprint (which was not certified by peer review) is the author/funder, who has granted medRxiv a license to display the preprint in perpetuity.

278 The quality-trimmed paired-end Illumina reads from the remaining 218 high-quality clade

$279 \mathrm{C} / \mathrm{H} 30$ isolates were mapped onto the chromosome of EC958 using SPANDx with default 280 parameters to generate annotated SNP/INDEL matrices. To account for recombination, 281 regions of high-density clustered SNPs ( $\geq 3$ SNPs found within a $100 \mathrm{bp}$ window) were 282 removed. Sites were excluded if a SNP was called in regions with less than half or greater 283 than 3-fold the average genome coverage on a genome-by-genome basis. SPANDx 284 generated an alignment of 4,354 non-recombinant, orthologous, biallelic core-genome SNPs 285 from the 219 strains. Lastly, a maximum likelihood (ML) phylogenetic tree from the nonrecombinant SNP alignment was generated using RAxML v8.2.10(47) (GTR-GAMMA correction) thorough optimisation of 20 distinct, randomized maximum parsimony trees, before adding 1,000 bootstrap replicates. The resulting phylogenetic tree was visualised using FigTree v1.4.4 (http://tree.bio.ed.ac.uk/software/figtree/) and EvolView v2(48, 49).

\subsection{Root-to-tip regression analysis}

A regression analysis was used to estimate the temporal signal in the clade C/H30 ST131 sub-lineage between the root-to-tip genetic distance using TempEst v1.5.15(50). The ML phylogenetic tree that was reconstructed from the alignment of 4,354 non-recombinant, orthologous, biallelic core-genome SNPs (as described above) was used as the input into ERR161304), and U004 (SRA: SRS456902)]. SPANDx was rerun using the same parameters as described above, only with the '-s' flag set to none to move straight to the comparative genomics and error correction section of the pipeline. The new alignment for Bayesian phylogenetic inference consisted of 4,150 non-recombinant, orthologous, biallelic coregenome SNPs from 215 clade C/H30 ST131 strains. The ML rebuilt using the methods above.

\subsection{Bayesian temporal analysis}

To further the temporal analysis, a time calibrated phylogenetic tree was generated with BEAST2 v2.6.1(51). The alignment of 4,150 SNPs was run through jModelTest v2.1.10(52, 53), which identified the GTR nucleotide substitution model as the best-fit evolutionary model. 
medRxiv preprint doi: https://doi.org/10.1101/2021.05.21.21257487; this version posted May 24, 2021. The copyright holder for this preprint (which was not certified by peer review) is the author/funder, who has granted medRxiv a license to display the preprint in perpetuity.

311 created using tip dates, a GTR substitution model, and a coalescent prior with a constant

312 population. Both models were tested with the Nested sampling Bayesian computation

313 algorithm v1.1.0 within the BEAST2 package with a particle count of 1, sub chain length of

3145,000 , and Epsilon of $1.0 \times 10^{-6}$. This analysis provides evidence in favour of the uncorrelated

315 relaxed clock model. Various population models were compared to ensure selection of the best-

316 fit model. These included the Bayesian skyline, coalescent constant, and exponential growth

317 population size change models. The Gamma Site Model Category Count was set to four and

318 the GTR substitution model rates determined from $\mathrm{jModelTest}$ were included (i.e., rate $\mathrm{AC}=$

$3190.94, \mathrm{AG}=3.16, \mathrm{AT}=1.10, \mathrm{CG}=0.14, \mathrm{CT}=3.12$, and $\mathrm{GT}=1.00)$. Notably, the initial clock

320 rate was set to $7.61 \times 10^{-4}$ (as estimated from the root-to-tip regression analysis in TempEST)

321 with a uniform distribution and an upper bound of 0.1 . All other priors were left as default. A

322 total of three independent Markov chain Monte Carlo (MCMC) generations for each analysis

323 were conducted for 100 million generations. Trees were sampled every 1,000 generations

324 which resulted in triplicate samples of 100,000 trees for each model test. All BEAST runs were

325 imported into Tracer v1.7.1 (http://github.com/beast-dev/tracer/) to assess statistics.

326 LogCombiner v2.5.0 (BEAST 2 package) then combined the replicated analyses for each

327 model with a $10 \%$ burn-in to assess convergence/appropriate sampled run. Finally,

328 TreeAnnotator v2.4.5 (BEAST 2 package) removed the $10 \%$ burn-in and generated maximum

329 clade credibility (MCC) trees for each run (established from 243 million trees), reporting

330 median values with a posterior probability limit set at 0.5 . FigTree was used to visualise the

331 annotated MCC trees. We determined the best-fitting tree model as the uncorrelated relaxed

332 exponential clock model with the Bayesian skyline population size change model based on the

333 mean tree likelihood scores (Table S8). 
medRxiv preprint doi: https://doi.org/10.1101/2021.05.21.21257487; this version posted May 24, 2021. The copyright holder for this preprint (which was not certified by peer review) is the author/funder, who has granted medRxiv a license to display the preprint in perpetuity.

\subsection{E. coli ST131 strains from Wales}

Previous genomic and multilocus sequence typing (MLST) investigations identified that

ECB cases were disproportionately caused by E. coli ST131 ( $n=187 / 720,26.0 \%)(54)$. This study involved $E$. coli $\mathrm{ST} 131$ isolates cultivated from blood specimens collected from twenty hospitals across six health boards within Wales (Figure S2). Of the 157 isolates collected over the study (between 2013 and 2014), 142 passed quality-control on the sequence data [females $n=70 / 142(49.3 \%)$, males $n=69 / 142(48.6 \%)$, no sex recorded $n=3 / 142(2.1 \%)]$. Patients were typically older, with a median age of 80 years (IQR: 70 to 87 years; range: 19 to 105 years), which reflects the known patient profile of ECB cases(1).

\subsection{Major ST131 clades are represented amongst ST131 circulating Wales}

The 142 draft genomes had a median total length of $5.20 \mathrm{Mb}$ (IQR: 5.10 to 5.27; range: 4.75 to $5.48 \mathrm{Mb}$ ), a median GC content of $50.7 \%$ (IQR: 50.7 to $50.8 \%$; range: 50.5 to $51.3 \%$ ), and a median N50 statistic of $199.59 \mathrm{~kb}$ (IQR: 102.39 to $245.60 \mathrm{~kb}$; range: 6.42 to $499.50 \mathrm{~kb}$ ). All 142 genomes are ST131, except for BA1243 and BA1279 (same Clonal Complex) that differ in the fumarate hydratase class II $(f u m C)$ and malate dehydrogenase $(m d h)$ genes respectively (Figure S3). The Welsh ST131 draft genomes have a high prevalence of chromosomal mutations conferring high level resistance (MICs $>32 \mathrm{mg} / \mathrm{L}$ ) to fluoroquinolones, where most ( $n=102 / 142,71.8 \%$ ) contain double variants in gyrA (D87N and S83L) and parC (E84V \& S80I). An additional ten genomes contain a single variant in gyrA (S83L) which usually confers low level resistance (MICs $0.5 \mathrm{mg} / \mathrm{L}$ ). The bla $a_{\mathrm{CTX}-\mathrm{M}-15}$ gene (CTX-M-1 group) is the most common ( $n=65 / 142,45.8 \%)$ AMR gene encoding ESBLs. The bla OXA-1 $_{\text {gene is also }}$ common $(n=62 / 142,43.7 \%)$ amongst Welsh strains, which encodes resistance to amoxicillin/clavulanic acid, and piperacillin/tazobactam (antibiotic/ $\beta$-lactamase inhibitor when in combination with ESBL genes). Notably, $36.6 \%(n=52 / 142)$ of the strains carry both blactX-

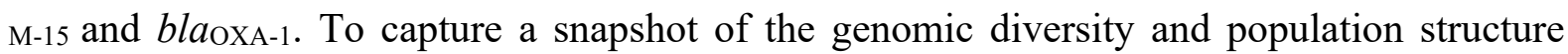
amongst ST131 strains circulating in Wales, the draft assemblies of the 142 genomes were contextualised with a global collection of ST131 cases sequenced elsewhere $(n=208)$ (Figure S4). The 13,758 non-recombinant core-genome SNP alignment represents a core-genome alignment of 2,575,140 bp relative to the 5,109,767 bp reference chromosome EC958. All three well-supported major ST131 clades (A, B, and C) are represented across Wales. While most 
medRxiv preprint doi: https://doi.org/10.1101/2021.05.21.21257487; this version posted May 24, 2021. The copyright holder for this preprint (which was not certified by peer review) is the author/funder, who has granted medRxiv a license to display the preprint in perpetuity.

367 isolates are located within clade $\mathrm{C} / H 30(n=103 / 142,72.5 \%)$, representatives from clade A $368(n=22 / 142,15.5 \%)$ and clade $\mathrm{B}(n=17 / 142,12.0 \%)$ are present at similar frequencies.

369

370

7.3 The majority of clade C/H30 ST131 isolates circulating Wales are ESBL-producing, conferring resistance to $3 \mathrm{GCs}$

To infer the phylogenetic relatedness of isolates and determine AMR gene carriage, we

373 created a core-genome SNP alignment of clade $\mathrm{C} / H 30$ strains only using SPANDx. This

374 alignment of global clade $\mathrm{C} / H 30$ strains $(n=219)$ comprises 4,354 non-recombinant

375 orthologous biallelic SNPs representing a $\sim 4,005,300$ bp core-genome (regions estimated to

376 the nearest $100 \mathrm{bp}$ with $\geq 95 \%$ coverage across all genomes) relative to the $5,109,767 \mathrm{bp}$

377 chromosome of EC958. Almost half $(n=102 / 219,46.6 \%)$ of our global clade $\mathrm{C} / H 30$ lineage

378 comprised isolates collected from bacteraemia cases across Wales (Figure 1; see branch lengths

379 expressed as SNPs in Figure S5). In our combined dataset, the majority of clade C/H30 ST131

380 strains belonged to sub-clade C2/H30Rx ( $n=151 / 219,68.9 \%)$, with sub-clade $\mathrm{C} 1 / H 30 \mathrm{R}$

$381(n=67 / 219,30.6 \%)$ less common. Sub-clade C2/H30Rx mostly comprised Welsh strains

$382(n=88 / 151,58.3 \%)$, whereas in sub-clade C1/H30R, the Welsh strains comprise only $20.9 \%$ of

383 the sub-lineage $(n=14 / 67)$. The majority $(n=68 / 102,66.7 \%)$ of these clade $\mathrm{C} / H 30$ isolates

384 demonstrate an ESBL-producing genotype. In terms of acquired resistance to $\beta$-lactams, CTX-

385 M-type metallo- $\beta$-lactamase genes were dominant, with the most prevalent being the

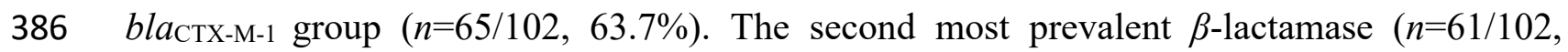

$38759.8 \%$ ) bla $\mathrm{OXA}_{-1}$, which encodes resistance to amoxicillin/clavulanic acid, and

388 piperacillin/tazobactam (antibiotic/ $\beta$-lactamase inhibitor). 
medRxiv preprint doi: https://doi.org/10.1101/2021.05.21.21257487; this version posted May 24, 2021. The copyright holder for this preprint (which was not certified by peer review) is the author/funder, who has granted medRxiv a license to display the preprint in perpetuity.

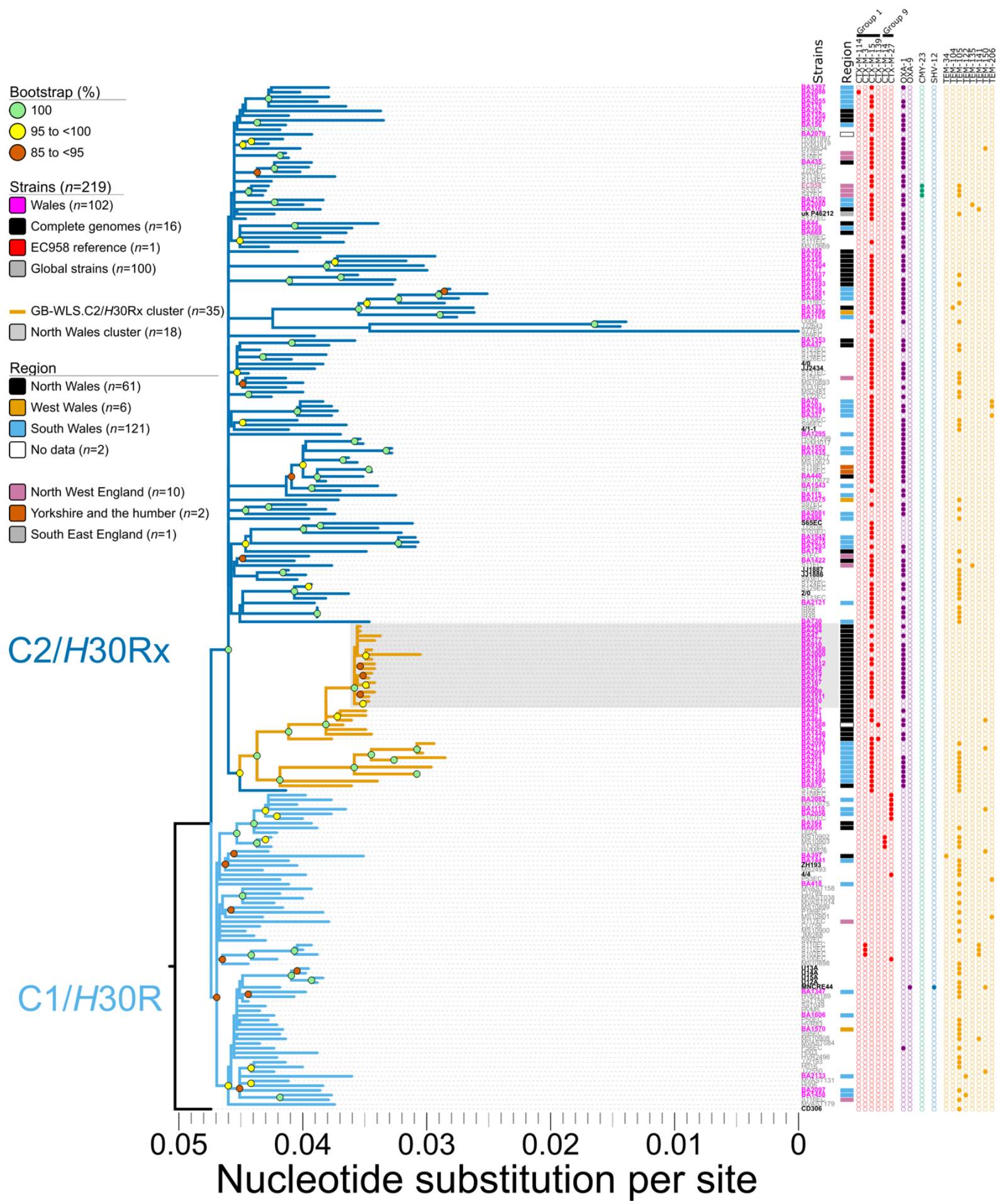

Figure 1. Maximum likelihood phylogeny of clade C/H30 Escherichia coli sequence type

4,354 non-recombinant orthologous biallelic core-genome single-nucleotide polymorphisms (SNPs) from 219 strains. Moderate recombination SNP density filtering in SPANDx (excluded regions with $\geq 3$ SNPs in a 100 bp window). SNPs are derived from read mapping to the reference chromosome EC958 (GenBank HG941718). Phylogenetic trees are rooted according to the CD306 (GenBank: CP013831) outgroup. Branch lengths represent nucleotide 
medRxiv preprint doi: https://doi.org/10.1101/2021.05.21.21257487; this version posted May 24, 2021. The copyright holder for this preprint (which was not certified by peer review) is the author/funder, who has granted medRxiv a license to display the preprint in perpetuity.

400

401

402

403

404

405

406

407

408

409

410

411

412

413

414

415

416

417

418

419

420

421

422

423

424

425

426

427

428

substitutions per site as indicated by the scale bar. Bootstrapping using 1,000 replicates demonstrates the robustness of the branches.

\subsection{The GB-WLS.C2/H30Rx Welsh cluster shares a common ancestor of North American origin}

Among the $\mathrm{C} 2 / H 30 \mathrm{Rx}$ population (Figure 1), there is a cluster of 35 isolates from Wales that are separated by a maximum pair-wise distance of 123 non-recombinogenic SNPs between strains BA264 (collected in South Wales in 2013) and BA2000 (collected in North Wales in 2014). Strains within this C2/H30Rx Welsh cluster (designated GB-WLS.C2/H30Rx) are closely related with a median pair-wise distance of 48 (IQR: 21 to 92) non-recombinogenic SNPs. The GB-WLS.C2/H30Rx sub-lineage has descended from a common ancestor (CA) shared with the clinical O25b:H4:K5 strain S125EC (SRA: ERS126605), which was cultivated in 2002 from a patient with a surgical wound in Canada(9), pointing towards the global dispersion of ST131. Isolates within GB-WLS.C2/H30Rx are distinguishable by six unique core-genome SNPs relative to EC958, two of which are in genes associated with fitness or virulence ( $c u s B$; cation efflux system mediating resistance to copper and silver and fepE; ferric enterobactin siderophore transport protein) (Table 1). Outside of the core-genome, strains within GB-WLS.C2/H30Rx (except for BA876) have lost region II of the K5 capsule loci, likely because of recombination, resulting in a loss of the K5 capsule production (Figure 2). In E. coli, group 2 capsular polysaccharides typically share conserved regions in the capsule loci (regions I and III). These conserved regions encode the transmembrane complex involved in the export and assembly of the capsular polysaccharides $(15,55,56)$. Region II is, however, serotype-specific and encodes for enzymes responsible for synthesizing the capsular polysaccharide. Strains within GB-WLS.C2/H30Rx have region II of the capsule locus replaced with two genes, the catB chloramphenicol-related O-acetyltransferase (xenobiotic acyltransferase [XAT]), conferring resistance to chloramphenicol and a HAD-IA family hydrolase, which has been resolved with the completion of the clinical strain $\mathrm{O} 25: \mathrm{H} 4$ collected in Saudi Arabia in 2014 (GenBank: CP015085). In the C2/H30Rx strain O25:H4, the low average guanine-cytosine content $(42.18 \%)$ of the $15.2 \mathrm{~kb}$ capsule locus suggests a foreign origin. 
medRxiv preprint doi: https://doi.org/10.1101/2021.05.21.21257487; this version posted May 24, 2021. The copyright holder for this preprint (which was not certified by peer review) is the author/funder, who has granted medRxiv a license to display the preprint in perpetuity. It is made available under a CC-BY-NC-ND 4.0 International license.

Table 1. Specific variants between Escherichia coli strain EC958 and GB-WLS.C2/H30Rx Position in EC958 601,912 632,160 $1,672,896$

$2,698,528$ $2,902,622$ 2,964,604 EC958

Cluster
Change $^{b}$

$\begin{array}{cr}\text { e }^{\boldsymbol{b}} & \text { Impact } \\ \text { Syn } & \text { LOW }\end{array}$
$\mathrm{Q}=$ >stop $\quad \mathrm{HIGH}$

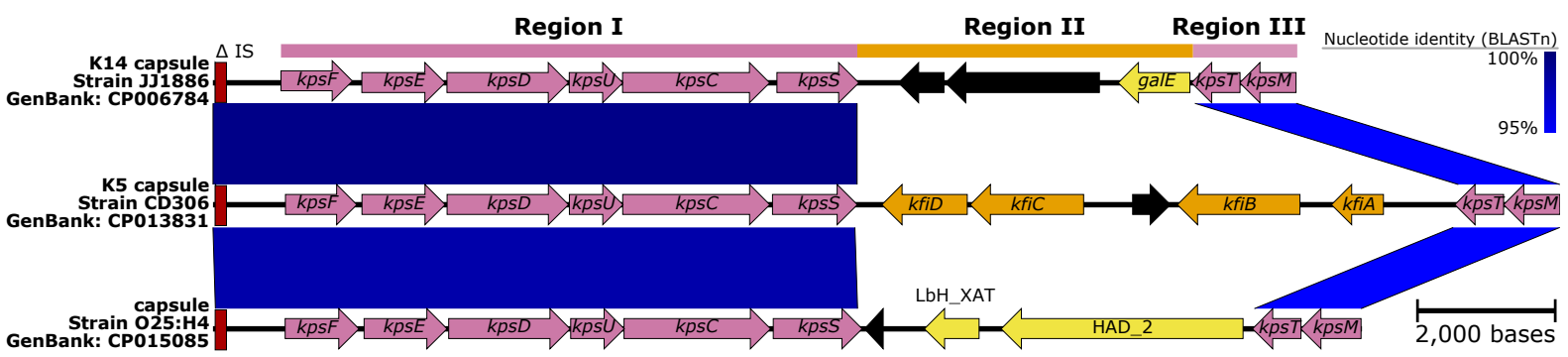
capsules in Escherichia coli. Nucleotide comparisons between the sub-clade C1/H30R genome JJ1886 and clade C/H30 outgroup genome CD306, highlighting differences between the K14 and K5 capsular region. Blue shading indicates nucleotide identity between sequences according to BLASTn (95 to 100\%). Key genomic regions are indicated: IS: red (185bp fragment from IS110 family), conserved capsular regions I and III: pink, differing capsular regions (region II): orange and yellow, other CDSs: black. Image created using Easyfig(57). separated by a maximum pair-wise distance of 30 (median: 11, IQR: 8 to 13) nonrecombinogenic SNPs, highlighting a small, local ST131 cluster. Isolates within this GBWLS.C2/H30Rx sub-cluster from North Wales are distinguishable by 10 unique SNPs and a single 1-bp deletion relative to EC958 (Table 2). Additionally, a single strain BA909 (collected in 2014), contained a SNP putatively conferring resistance to rifampicin in rpoB (Q513L)(58). Due to anonymisation of epidemiological data, it is unclear whether isolates BA434 and BA1512 (separated by 9 SNPs, collected 257 days apart) and BA810 and BA909 (separated by 12 SNPs, collected 90 days apart) were sampled from the same patient. This analysis however, identified two samples, BA43 and BA910 separated by a single SNP, from two different patients (both male, aged 87 and 77-years) from two different hospitals, 239 days apart. This sequence similarity may suggest that these cases are linked by transmission or were 
medRxiv preprint doi: https://doi.org/10.1101/2021.05.21.21257487; this version posted May 24, 2021. The copyright holder for this preprint (which was not certified by peer review) is the author/funder, who has granted medRxiv a license to display the preprint in perpetuity. It is made available under a CC-BY-NC-ND 4.0 International license.

453 from two individual patients collected two days apart from within the same hospital are separated by only two SNPs, suggestive of an epidemiological link.

455

Table 2. Variants separating Escherichia coli strain EC958 and the North Wales sub-cluster

\begin{tabular}{|c|c|c|c|c|c|c|c|}
\hline $\begin{array}{l}\text { Position } \\
\text { in EC958 }\end{array}$ & EC958 & Cluster & Change $^{b}$ & Impact & Codon & Gene & Product \\
\hline 900,998 & $\mathbf{G}$ & $A$ & $W=>$ stop & $\mathrm{HIGH}$ & 159 & $n f S A$ & Oxygen-insensitive NADPH nitroreductase \\
\hline $1,052,210$ & G & $T$ & $\mathrm{G}=>\mathrm{C}$ & MODERATE & 403 & ycaQ & Uncharacterized protein \\
\hline $1,113,811$ & C & $T$ & Syn & LOW & 74 & $a p p B$ & Cytochrome bd-II ubiquinol oxidase subunit 2 \\
\hline $1,842,716$ & $\mathbf{T}$ & c & $S=>P$ & MODERATE & 2 & ydis & $\begin{array}{r}\text { Probable electron transfer flavoprotein-quinone } \\
\text { oxidoreductase }\end{array}$ \\
\hline $2,372,060$ & $\mathbf{G}$ & $A$ & Syn & LOW & 413 & gatZ & D-tagatose-1,6-bisphosphate aldolase subunit \\
\hline $2,405,414$ & CG & C & Deletion & MODIFIER & & & \\
\hline $2,468,793$ & $\mathbf{G}$ & $A$ & Syn & LOW & 92 & yeiR & Zinc-binding GTPase \\
\hline $2,485,972$ & $\mathbf{A}$ & G & Syn & LOW & 302 & yejM & Inner membrane protein \\
\hline $3,196,673$ & G & $A$ & Syn & LOW & 258 & $x a n Q$ & Xanthine permease \\
\hline $4,706,103$ & C & $G$ & $W=>S$ & MODERATE & 31 & $m d t N$ & Multidrug resistance protein \\
\hline $4,734,158$ & $\mathbf{A}$ & $G$ & $\mathrm{~S}=>\mathrm{P}$ & MODERATE & 205 & bass & Sensor protein \\
\hline
\end{tabular}

456

457

7.5 The root-to-tip distance is consistent with the BEAST2 temporal signal and phylogenetic reconstruction

459

The divergence time and evolutionary distance for the 215 clade C/H30 ST131 genomes

460 (four strains were removed as they did not match the evolutionary trajectory of the remaining 461 strains) showed a linear relationship (correlation coefficient $=0.59$ ), with the regression analysis 462 in TempEST indicating that the genomes accumulate mutations at a rate of $7.61 \times 10^{-4}$ 463 substitutions per site per year $\left(R^{2}=0.35\right)$ (Figure $\left.\mathrm{S} 6\right)$. The time to the most recent common 464 ancestor (MRCA) is estimated at the end of 1993 (95\% confidence interval: 1989 to 1996). 465 Likewise, BEAST2 pinpoints the time to MRCA to 1994 [95\% highest posterior density 466 (HPD): 1986 to 1998] (Figure 3) (based on median node height) and estimates a mutation 467 rate of $6.87 \times 10^{-4}$ substitutions per site per year (95\% HPD: $5.10 \times 10^{-4}$ to $\left.8.60 \times 10^{-4}\right)$. This 468 translates to 2.85 fixated SNPs per year per genome (95\% HPD: 2.12 to 3.57), which means 469 that approximately six SNPs can be expected to differ between two isolates sharing a MRCA 470 one year back in time. A previous study highlighted the within-host diversity of ST131 residing 471 in the intestinal tract of a single patient(17); where strains U13A and U14A were collected nine 472 months apart. Here, these strains are depicted to be separated by seven SNPs. This analysis 473 indicates that the CA to U13A and U14A existed approximately two (95\% HPD: one to five) 474 years prior to the initial collection of U13A in 2013, which gives credibility to our phylogenetic 475 reconstruction. To correct for ascertainment bias, our dataset describes one SNP for every 476963.9 bases across the $\sim 4 \mathrm{Mb}$ core-genome. This translates to a genome-wide mutation rate of $4777.15 \times 10^{-7}$ mutations/year/site relative to genome size, which is consistent with previous large- 
medRxiv preprint doi: https://doi.org/10.1101/2021.05.21.21257487; this version posted May 24, 2021. The copyright holder for this preprint (which was not certified by peer review) is the author/funder, who has granted medRxiv a license to display the preprint in perpetuity.

$\left.479{ }^{7}(60)\right]$.

480

481

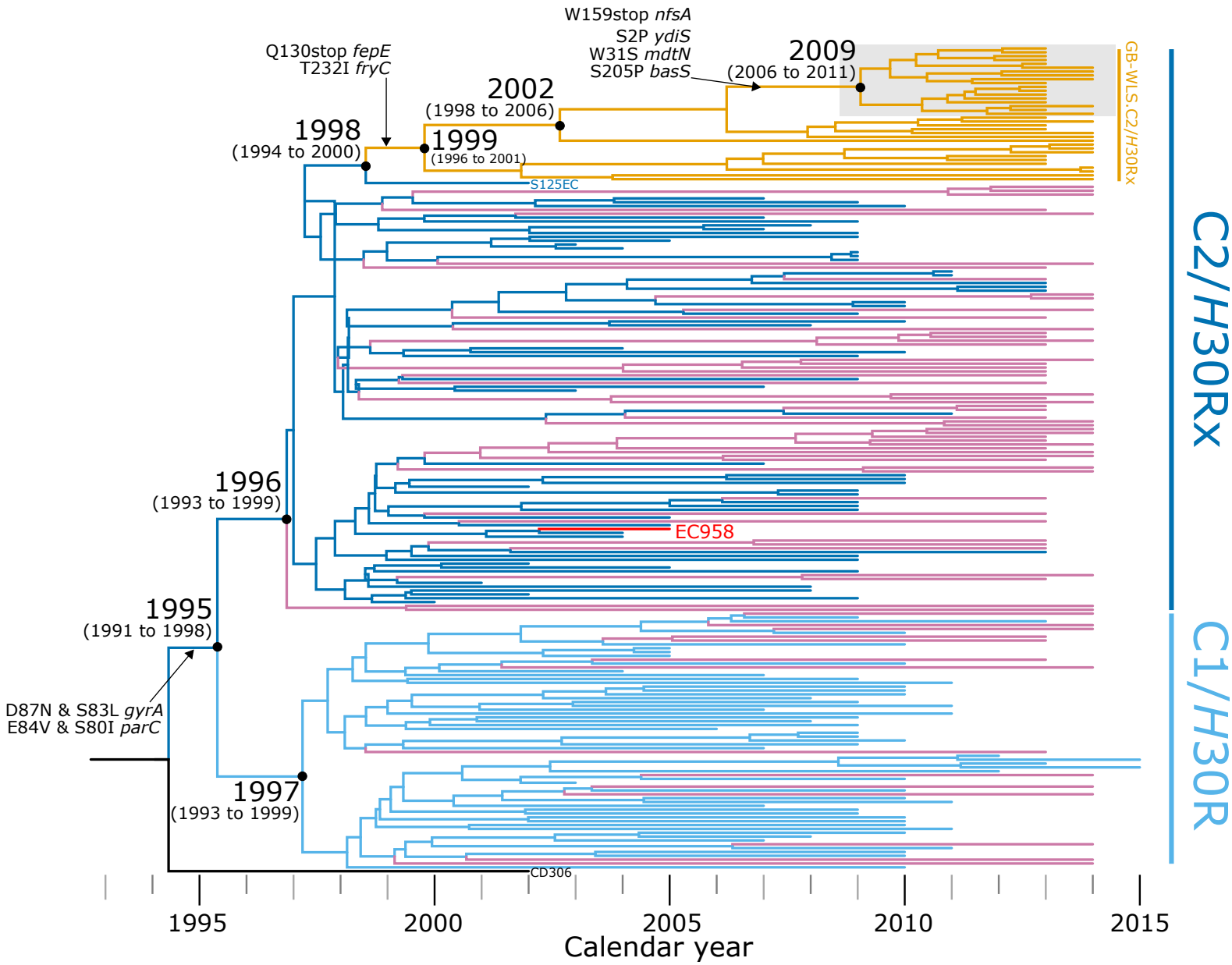

Figure 3. Evolutionary reconstruction of clade C/H30 Escherichia coli sequence type (ST)131. A time-calibrated maximum clade credibility tree inferred from 4,150 nonrecombinant orthologous biallelic core-genome single-nucleotide polymorphisms (SNPs). Moderate recombination SNP density filtering in SPANDx (excluded regions with $\geq 3$ SNPs in a $100 \mathrm{bp}$ window). SNPs are derived from read mapping to the reference chromosome EC958 (GenBank: HG941718). X-axis represents the emergence time estimates. Isolates from Wales are shown with reddish purple or orange branches.

\section{Discussion}

Recent investigations across England have shown the value of identifying clonal lineages using high-resolution analyses obtainable through WGS for surveillance efforts(4, 7). For example, ECB in England is shown to represent a spill-over from strains circulating in the wider human population(4). This genomic epidemiology study provides a snapshot of the population structure of E. coli ST131 associated with bacteraemia in Wales. A final total of 
medRxiv preprint doi: https://doi.org/10.1101/2021.05.21.21257487; this version posted May 24, 2021. The copyright holder for this preprint

(which was not certified by peer review) is the author/funder, who has granted medRxiv a license to display the preprint in perpetuity.

It is made available under a CC-BY-NC-ND 4.0 International license.

496

497

498

499

500

501

502

503

504

505

506

507

508

509

510

511

512

513

514

515

516

517

518

519

520

521

522

523

524

525

526

527

528

142 E. coli ST131 strains collected across Wales underwent WGS and were contextualised for their genetic relationship with global ST131 strains through available datasets. To the knowledge of the study authors, this represents the first characterisation of the epidemiological and spatiotemporal nature of ST131 circulating in Wales.

This study used genomic epidemiology to identify clusters of strains, possibly suggesting patients were colonised/infected from the same source, and demonstrates the benefits of incorporating WGS, stringent quality control and epidemiological data for public health surveillance and investigations. Initial phylogenetic relationships were first inferred from SNPs to depict an overall tree topology that represent core-genome alignments of draft genome assemblies. These initial analyses found that, while all three major clades well-supported by the literature are represented in ST131 strains circulating in Wales, the predominant lineage is defined by a high prevalence of chromosomal mutations conferring resistance to fluoroquinolones and the presence of AMR genes encoding ESBLs (clade C/H30, particularly sub-clade $\mathrm{C} 2 / H 30 \mathrm{Rx})$. Subsequent analyses were undertaken to compile a much higher resolution of inter-strain relationships by exploiting read mapping of short-read sequence data to a chromosome previously sequenced. These analyses offer the opportunity for the reevaluation of the ST131 clade C/H30 evolutionary trajectory previously characterised(4, 10, $59,61)$ and confirms the requirement for careful re-analysis of publicly available genomic data, with stringent quality control requirements. The study results highlight the emergence and dissemination of a distinct $\mathrm{C} 2 / \mathrm{H} 30 \mathrm{Rx}$ sub-cluster because of an introduction into Wales circa 1999 (sub-clade C2/H30Rx; 95\% HPD: 1996 to 2001), which has been named GBWLS.C2/H30Rx. The limited genomic diversity (median pair-wise distance of 11 SNPs) amongst a distinct GB-WLS.C2/H30Rx sub-cluster from North Wales (which emerged in 2009) suggests that the actual reservoir of infection reservoir was not confined to a single nosocomial setting. Analyses into local clusters and transmissions can be highly discriminatory and could become a routine part of surveillance programs with the generation of highly accurate short-reads, and high throughput, from Illumina's short-read sequencing technologies.

Of particular concern is the high rates of ESBL carriage (66.7\%) in ST131 bacteraemia isolates in Wales (clade $\mathrm{C} / \mathrm{H} 30$ ), particularly those conferring resistance to $3 \mathrm{GCs}$, from the bla $(n=65 / 102,63.7 \%)$. These rates are lower than studies in other jurisdictions; $95 \%$ of cephalosporin-resistant ST131 isolates in Australia, New Zealand and Singapore showed 
medRxiv preprint doi: https://doi.org/10.1101/2021.05.21.21257487; this version posted May 24, 2021. The copyright holder for this preprint (which was not certified by peer review) is the author/funder, who has granted medRxiv a license to display the preprint in perpetuity.

529 isolate carriage of bla $a_{\mathrm{CTX}-\mathrm{M}-15}$ or bla $_{\mathrm{CTX}-\mathrm{M}-27}(6)$ and $82.2 \%$ of cefotaxime-resistant UPEC

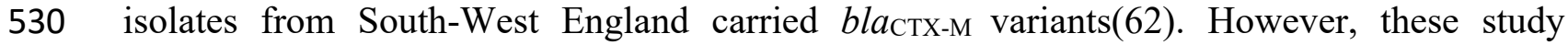
531 methodologies differed by specifically selecting 3GC-resistant isolates for inclusion, whereas 532 this study is population-based and not biased by AMR selection. The rapid global emergence 533 and sustained dominance of clade C/H30 ST131 and the characterisation of the unique ST131 534 Welsh sub-lineage (GB-WLS.C2/H30Rx) highlights the requirement for timely and continuous 535 yearly genomic surveillance, which could facilitate rapid and targeted interventions, for a 536 successful infection control, antimicrobial stewardship, and public health responses. The 537 Office for National Statistics has previously collated mortality data where E. coli septicaemia 538 or sepsis were explicitly mentioned on death certificates in Wales between 2001 and 2015(1).

539 Taken together, this collated mortality data combined with genomic surveillance can support 540 the National Health Service (NHS) in Wales by providing timely data for action on serious 541 infections from both healthcare- and community-associated origins with little delay.

543 This study estimates the emergence of fluoroquinolone-resistant C/H30 ST131 circa 1995 544 (95\% HPD: 1991 to 1998). This differs from the previously reported dates from Ben Zakour et 545 al.(10), Stoesser et al.(61), and Kallonen et al.(4), that estimate 1987 (95\% HPD: 1983 to 546 1992), 1982 (95\% HPD: 1948 to 1995), and circa 1987, respectively. In contrast, after 547 analysing 794 ST131 genomes, Ludden et al.(59) supports our findings and pinpoints the 548 emergence of the fluoroquinolone-resistant C/H30 ancestor to 1992 (95\% HPD 1989 to 1994). 549 While the posterior mean/median node heights for the clades vary between studies, it is 550 important to recognise that the 95\% HPD intervals overlap. The variation in study results is 551 likely due to the enhanced methodology utilised, including: stringent quality control metrics, improved versions of tools and methods, use of a high quality clade $\mathrm{C}$ reference genome, the exclusion of clade B ST131 strains, and the inclusion of a fluoroquinolone sensitive clade $\mathrm{C} / \mathrm{H} 30$ outgroup strain (CD306).

556 These highly discriminatory analyses reveal multiple introductions of sub-clade C2/H30Rx 557 into Wales before an emergence circa 1999 (95\% HPD: 1996 to 2001) of the unique clonal 558 sub-lineage (GB-WLS.C2/H30Rx), which shares a CA of North American origin. These unique strains (GB-WLS.C2/H30Rx) were related with a median pair-wise SNP distance of 48 non-recombinogenic SNPs, which could indicate localised transmission with an unidentified infection reservoir. The CA to this unique strain (GB-WLS.C2/H30Rx) is distinguishable from 
medRxiv preprint doi: https://doi.org/10.1101/2021.05.21.21257487; this version posted May 24, 2021. The copyright holder for this preprint

(which was not certified by peer review) is the author/funder, who has granted medRxiv a license to display the preprint in perpetuity.

It is made available under a CC-BY-NC-ND 4.0 International license.

562 that shared with the basal S125EC strain by an impairment of ferric enterobactin synthesis and

563

564

565

566

567

568

569

570

571

572

573

574

575

576

577

578

579 The study design describes cases of bacteraemia, with confirmed blood cultures, caused by transport due to a premature termination because of a Q130stop codon in fepE, and the loss of a region encompassing the capsular biosynthesis genes for a K5 capsular antigen. Notably, both enterobactin and the capsule are known UPEC virulence factors. Whether the inactivation of these genes resulted in a decrease in virulence remains to be elucidated and represents a research question for future investigation. For strains within GB-WLS.C2/H30Rx, region II of the capsular loci was replaced with a chloramphenicol acetyltransferase (CAT) and HAD-IA family hydrolase. CATs inactivate chloramphenicol by generating derivatives like 1-acetoxy chloramphenicol, 3-acetoxy chloramphenicol, or 1,3-diacetoxy chloramphenicol. These derivatives are unable to inhibit bacterial growth and survival as interruption of the ribosomal peptidyl-transferase is no longer possible $(63,64)$. Further, the identification of a local cluster within North Wales, MRCA emerged in 2009, with very closely related strains differing by a median of 11 non-recombinant pair-wise SNPs, suggests that there was possible direct transmission between these individuals. Although, the anonymisation of patient data limits confirmation of an actual nosocomial infection reservoir and evidence of negative (or positive) culture on admission would be required for any certainty.

580

581 ST131 in Wales. This is likely a consequence of UTI treatment failure due to AMR, although

582 further research is needed to establish links between confirmed blood and urine isolates. Therefore, this study may not represent the whole population structure of GB-WLS.C2/H30Rx in UTIs in Wales. In this circumstance, one would expect increased rates of AMR, and thus it is likely that the population structure of all GB-WLS.C2/H30Rx is to be less resistant than might be expected based upon the results reported here. Globally there is a necessity to acquire a deeper understanding of the population structure of UPEC, so that UPEC strains that are more likely to result in treatment failure and progress to bacteraemia can be identified as a risk factor. This can be achieved through the identification and tracking of genomic sequences (e.g. AMR determinants and virulence factors) as indicators for predicting phenotypic characteristics. One of the key strengths of our study was our ability to avoid a temporal or geographical bias in our dataset by contextualising the ST131 Welsh strains with global isolates. This lack of bias was reflected by our population expansion timeline which coincides with the initial detection of ST131 in the UK in 2003(4), before becoming the predominant clone ( $n=52 / 88,59.1 \%)$ in the Northwest of England between 2004 and 2006(7). Previous studies of whole-genome SNP 
medRxiv preprint doi: https://doi.org/10.1101/2021.05.21.21257487; this version posted May 24, 2021. The copyright holder for this preprint (which was not certified by peer review) is the author/funder, who has granted medRxiv a license to display the preprint in perpetuity.

595 discovery for phylogenetics $(6,9,10)$ have used the Bowtie $2(37,65)$ or the SHRiMP(66) read 596 aligner with FreeBayes(67) within the Nesoni pipeline (https://github.com/Victorian597 Bioinformatics-Consortium/nesoni). However, SPANDx was utilised for the methodology 598 employed in this study as it has been peer reviewed(46) and is under regular development, with 599 v4.0.1 released on 02 April 2020. Additionally, previous quality assurance analyses using 600 SPANDx have been reported(68) to ensure; a single mixed strain does not affect tree topology 601 and phylogenetic inference, and the importance of assessing datasets for the presence of mixed 602 strains prior to phylogenetic analyses.

603

604

\subsection{Conclusion}

605

Genomic epidemiological analyses on 142 ST131 strains associated with bacteraemia 606 across Wales between 2013 and 2014 were performed using whole-genome sequencing. This research demonstrates the requirement to reanalyse publicly available genomic data, with

608 stringent quality control, to improve the evolutionary trajectory of the ST131 clade $\mathrm{C} / H 30$ previously characterised. This study showed geographical clustering of sub-clade $\mathrm{C} 2 / H 30 \mathrm{Rx}$

610 in North Wales; characterised by genotypic resistance to third-generation cephalosporins, 611 fluoroquinolones, chloramphenicol, and nitrofurantoin. This emergence follows the 612 introduction of a single sub-lineage into Wales circa 1999 and its expansion and persistence, 613 which the authors have named GB-WLS.C2/H30Rx. This study highlights the need to 614 incorporate whole-genome sequencing with epidemiological data and a 'One Health' approach 615 to identify potential infection reservoirs in the environment, which will allow for the 616 identification of ST131 transmission dynamics between healthcare settings and the community. 617 This study displays a novel localised cluster of ST131 bacteraemia in Wales captured between 6182013 and 2014. By gaining a detailed understanding of significant E. coli bacteraemia strains, 619 it should be possible to develop targeted public health measures to reduce the risk of $E$. coli 620 bacteraemia and act to combat the rise of antimicrobial resistance.

621

622 9. Data Bibliography

623 1. White R.T. et al. BioProject PRJNA729115 (2021).

624 2. Kidsley A. K. et al. BioProject PRJNA627752 (2020).

625 3. Johnson, T. J. et al. BioProject PRJNA307507 (2016).

626 4. Johnson, T. J. et al. BioProject PRJNA311313 (2016). 
medRxiv preprint doi: https://doi.org/10.1101/2021.05.21.21257487; this version posted May 24, 2021. The copyright holder for this preprint (which was not certified by peer review) is the author/funder, who has granted medRxiv a license to display the preprint in perpetuity.

627 5. Petty, N. K. et al. BioProject PRJEB2968 (2014).

628 6. Price, L. B. et al. BioProject PRJNA211153 (2013).

629 7. Andersen, P. S. et al. BioProject PRJNA218163 (2013).

630 8. Totsika, M. et al. BioProject PRJEA61443 (2011).

631 9. Toh H. et al., BioProject PRJDA19053 (2010).

632

633 10. Author statements

634

\subsection{Authors and contributors}

Conceptualisation: R.T.W. Investigation: R.T.W. Funding was acquired by T.R.C. and computational resources were supported by S.A.B. Formal analysis: R.T.W. Wet-lab Antimicrobial Chemotherapy Unit (SACU) at Public Health Wales, University Hospital Wales, T.R.C., and R.T.W. Illumina sequencing was done at the Oxford Genomics Centre and 640 MicrobesNG at the University of Birmingham. Supervision: T.R.C., B.M.F., and S.A.B. 641 Writing (Original Draft Preparation): R.T.W. Writing (Review and Editing): R.T.W., M.J.B., 642 C.R.B., J.M.A., M.W., L.S.J., R.A.H., M.M., M.M.A., B.M.F., T.R.C., and S.A.B. All authors have read and approved the final version of the manuscript.

644

10.2 Conflicts of interest

646

The authors declare that there are no conflicts of interest.

647

\subsection{Funding information}

This work received funding for whole-genome sequencing from Public Health Wales NHS 650 Trust (United Kingdom) and a Wellcome Institutional Strategic Support Fund (ISSF) award to 651 Cardiff University (United Kingdom).

652

\subsection{Ethical approval}

This work was undertaken on stored bacterial cultures and no additional clinical samples 655 were collected from any persons to facilitate this study. Patient anonymity was maintained by 
medRxiv preprint doi: https://doi.org/10.1101/2021.05.21.21257487; this version posted May 24, 2021. The copyright holder for this preprint (which was not certified by peer review) is the author/funder, who has granted medRxiv a license to display the preprint in perpetuity. It is made available under a CC-BY-NC-ND 4.0 International license.

\subsection{Acknowledgements}

We thank the Public Health Wales laboratories and the Specialist Antimicrobial Chemotherapy Unit at University Hospital Wales for their contributions from the national public health surveillance of bacteraemia cases in Wales. We acknowledge the facilities, and the scientific and technical assistance of staff at the Oxford Genomics Centre and MicrobesNG at the University of Birmingham. This research was supported by QRIScloud and by use of the Nectar Research Cloud. The Nectar Research Cloud is a collaborative Australian research platform supported by the National Collaborative Research Infrastructure Strategy (NCRIS). Sequence data are uploaded and stored on the centralised Cloud Infrastructure for Microbial Bioinformatics (MRC-CLIMB) server, which is funded by the Medical Research Council (MRC) (grant codes MR/L015080/1 and MR/T030062/1). The author would like to thank Derek Sarovich and Erin Price (GeneCology Research Centre at the University of the Sunshine Coast, and the Sunshine Coast Health Institute) and Thomas Cuddihy (QFAB Bioinformatics and Research Computing Centre, The University of Queensland) for high-performance computing support and helpful discussions about software functionality.

\section{References}

1. Office for National Statistics. Deaths involving E. coli septicaemia, deaths registered in Wales between 2001 and 2015. London, United Kingdom: Office for National Statistics; 2016. Available from: https://www.ons.gov.uk/peoplepopulationandcommunity/birthsdeathsandmarriages/deaths/adhocs/006005de athsinvolvingecolisepticaemiadeathsregisteredinwalesbetween2001and2015 [Accessed 05 May 2021]

2. Wozniak TM, Bailey EJ, Graves N. Health and economic burden of antimicrobial-resistant infections in Australian hospitals: a population-based model. Infection Control \& Hospital Epidemiology 2019;40:320-327 doi: 10.1017/ice.2019.2

3. Riley LW. Pandemic lineages of extraintestinal pathogenic Escherichia coli. Clinical Microbiology and Infection 2014;20:380-390 doi: 10.1111/1469-0691.12646

4. Kallonen T, Brodrick HJ, Harris SR, Corander J, Brown NM, Martin V, et al. Systematic longitudinal survey of invasive Escherichia coli in England demonstrates a stable population structure only transiently disturbed by the emergence of ST131. Genome Research 2017;27:1437-1449 doi: 10.1101/gr.216606.116

5. Day MJ, Doumith M, Abernethy J, Hope R, Reynolds R, Wain J, et al. Population structure of Escherichia coli causing bacteraemia in the UK and Ireland between 2001 and 2010. Journal of Antimicrobial Chemotherapy 2016;71:2139-2142 doi: 10.1093/jac/dkw145

6. Harris PNA, Ben Zakour NL, Roberts LW, Wailan AM, Zowawi HM, Tambyah PA, et al. Whole genome analysis of cephalosporin-resistant Escherichia coli from bloodstream infections in Australia, New Zealand and Singapore: high prevalence of CMY-2 producers and ST131 carrying bla 27. Journal of Antimicrobial Chemotherapy 2018;73:634-642 doi: 10.1093/jac/dkx466

7. Lau SH, Reddy S, Cheesbrough J, Bolton FJ, Willshaw G, Cheasty T, et al. Major uropathogenic Escherichia coli strain isolated in the northwest of England identified by multilocus sequence typing. Journal of Clinical Microbiology 2008;46:1076-1080 doi: 10.1128/JCM.02065-07

8. Johnson JR, Johnston B, Clabots C, Kuskowski MA, Castanheira M. Escherichia coli sequence type ST131 as the major cause of serious multidrug-resistant E. coli infections in the United States. Clinical Infectious Diseases 2010;51:286-294 doi: 10.1086/653932 
medRxiv preprint doi: https://doi.org/10.1101/2021.05.21.21257487; this version posted May 24, 2021. The copyright holder for this preprint (which was not certified by peer review) is the author/funder, who has granted medRxiv a license to display the preprint in perpetuity. It is made available under a CC-BY-NC-ND 4.0 International license.

9. Petty NK, Ben Zakour NL, Stanton-Cook M, Skippington E, Totsika M, Forde BM, et al. Global dissemination of a multidrug resistant Escherichia coli clone. Proceedings of the National Academy of Sciences of the United States of America 2014;111:5694-5699 doi: 10.1073/pnas.1322678111

10. Ben Zakour NL, Alsheikh-Hussain AS, Ashcroft MM, Khanh Nhu NT, Roberts LW, Stanton-Cook M, et al. Sequential acquisition of virulence and fluoroquinolone resistance has shaped the evolution of Escherichia coli ST131. mBio 2016; 7:e00347-16 doi: 10.1128/mBio.00347-16

11. Totsika M, Beatson SA, Sarkar S, Phan MD, Petty NK, Bachmann N, et al. Insights into a multidrug resistant Escherichia coli pathogen of the globally disseminated ST131 lineage: genome analysis and virulence mechanisms. PLOS ONE 2011;6 doi: 10.1371/journal.pone.0026578

12. Gibreel TM, Dodgson AR, Cheesbrough J, Bolton FJ, Fox AJ, Upton M. High metabolic potential may contribute to the success of ST131 uropathogenic Escherichia coli. Journal of Clinical Microbiology 2012;50:3202-3207 doi: 10.1128/JCM.01423-12

13. Totsika M, Kostakioti M, Hannan TJ, Upton M, Beatson SA, Janetka JW, et al. A FimH inhibitor prevents acute bladder infection and treats chronic cystitis caused by multidrug-resistant uropathogenic Escherichia coli ST131. The Journal of Infectious Diseases 2013;208:921-928 doi: 10.1093/infdis/jit245

14. Phan MD, Peters KM, Sarkar S, Lukowski SW, Allsopp LP, Gomes Moriel D, et al. The serum resistome of a globally disseminated multidrug resistant uropathogenic Escherichia coli clone. PLOS Genetics 2013;9:e1003834 doi: 10.1371/journal.pgen.1003834

15. Goh KGK, Phan MD, Forde BM, Chong TM, Yin WF, Chan KG, et al. Genome-wide discovery of genes required for capsule production by uropathogenic Escherichia coli. mBio 2017;8 doi: 10.1128/mbio.0155817

16. Mathers AJ, Peirano G, Pitout JD. The role of epidemic resistance plasmids and international high-risk clones in the spread of multidrug-resistant Enterobacteriaceae. Clinical Microbiology Reviews 2015;28:565591 doi: 10.1128/cmr.00116-14

17. Forde BM, Roberts LW, Phan MD, Peters KM, Fleming BA, Russell CW, et al. Population dynamics of an Escherichia coli ST131 lineage during recurrent urinary tract infection. Nature Communications 2019;10:3643 doi: 10.1038/s41467-019-11571-5

18. Coque TM, Novais A, Carattoli A, Poirel L, Pitout J, Peixe L, et al. Dissemination of clonally related Escherichia coli strains expressing extended-spectrum beta-lactamase CTX-M-15. Emerging Infectious Diseases 2008;14:195-200 doi: 10.3201/eid1402.070350

19. Peirano G, Pitout JD. Molecular epidemiology of Escherichia coli producing CTX-M beta-lactamases: the worldwide emergence of clone ST131 O25:H4. International Journal of Antimicrobial Agents 2010;35:316321 doi: 10.1016/j.ijantimicag.2009.11.003

20. Johnson JR, Johnston B, Clabots C, Kuskowski MA, Pendyala S, Debroy C, et al. Escherichia coli sequence type ST131 as an emerging fluoroquinolone-resistant uropathogen among renal transplant recipients. Antimicrobial Agents and Chemotherapy 2010;54:546-550 doi: 10.1128/AAC.01089-09

21. National Institute for Clinical Excellence. Pyelonephritis (acute): antimicrobial prescribing. London, United Kingdom: Public Health England; 2018. Available from: https:/www.nice.org.uk/guidance/ng111 [Accessed 19 May 2021]

22. Livermore DM, Canton R, Gniadkowski M, Nordmann P, Rossolini GM, Arlet G, et al. CTX-M: changing the face of ESBLs in Europe. Journal of Antimicrobial Chemotherapy 2007;59:165-174 doi: $10.1093 / \mathrm{jac} / \mathrm{dk1} 483$

23. Public Health England. English surveillance programme for antimicrobial utilisation and resistance (ESPAUR) report. London, United Kingdom; 2019. Available from: https://assets.publishing.service.gov.uk/government/uploads/system/uploads/attachment_data/file/936199/E SPAUR_Report_2019-20.pdf [Accessed 19 May 2021]

24. Heginbothom M, Howe R, Davies E. Antibacterial resistance in Wales 2008-2017. Cardiff, United Kingdom: Public Health $\quad$ Wales; $2018 . \quad$ Available http://www.wales.nhs.uk/sitesplus/documents/888/Antimicrobial\%20Resistance\%20in\%20Wales\%2020082017\%20v1.pdf [Accessed 19 May 2021]

25. Peirano G, Schreckenberger PC, Pitout JD. Characteristics of NDM-1-producing Escherichia coli isolates that belong to the successful and virulent clone ST131. Antimicrobial Agents and Chemotherapy 2011;55:2986-2988 doi: 10.1128/AAC.01763-10 
medRxiv preprint doi: https://doi.org/10.1101/2021.05.21.21257487; this version posted May 24, 2021. The copyright holder for this preprint (which was not certified by peer review) is the author/funder, who has granted medRxiv a license to display the preprint in perpetuity. It is made available under a CC-BY-NC-ND 4.0 International license.

26. Morris D, McGarry E, Cotter M, Passet V, Lynch M, Ludden C, et al. Detection of OXA-48 carbapenemase in the pandemic clone Escherichia coli O25b:H4-ST131 in the course of investigation of an outbreak of OXA-48-producing Klebsiella pneumoniae. Antimicrobial Agents and Chemotherapy 2012;56:4030-4031 doi: 10.1128/AAC.00638-12

27. National Institute for Clinical Excellence. Urinary tract infection (lower): antimicrobial prescribing. London, United Kingdom: Public Health England; 2018. Available from: https://www.nice.org.uk/guidance/ng109 [Accessed 19 May 2021]

28. Zerbino DR, Birney E. Velvet: algorithms for de novo short read assembly using de Bruijn graphs. Genome Research 2008;18:821-829 doi: 10.1101/gr.074492.107

29. Boetzer M, Pirovano W. Toward almost closed genomes with GapFiller. Genome Biology 2012;13:R56 doi: 10.1186/gb-2012-13-6-r56

30. Assefa S, Keane TM, Otto TD, Newbold C, Berriman M. ABACAS: algorithm-based automatic contiguation of assembled sequences. Bioinformatics 2009;25:1968-1969 doi: 10.1093/bioinformatics/btp347

31. Tsai IJ, Otto TD, Berriman M. Improving draft assemblies by iterative mapping and assembly of short reads to eliminate gaps. Genome Biology 2010;11:R41 doi: 10.1186/gb-2010-11-4-r41

32. Boetzer M, Henkel CV, Jansen HJ, Butler D, Pirovano W. Scaffolding pre-assembled contigs using SSPACE. Bioinformatics 2011;27:578-579 doi: 10.1093/bioinformatics/btq683

33. Walker BJ, Abeel T, Shea T, Priest M, Abouelliel A, Sakthikumar S, et al. Pilon: an integrated tool for comprehensive microbial variant detection and genome assembly improvement. PLOS ONE 2014;9:e1 12963 doi: 10.1371/journal.pone.0112963

34. Chevreux B, Pfisterer T, Drescher B, Driesel AJ, Muller WE, Wetter T, et al. Using the miraEST assembler for reliable and automated mRNA transcript assembly and SNP detection in sequenced ESTs. Genome Research 2004;14:1147-1159 doi: 10.1101/gr.1917404

35. Darling AC, Mau B, Blattner FR, Perna NT. Mauve: multiple alignment of conserved genomic sequence with rearrangements. Genome Research 2004;14:1394-1403 doi: 10.1101/gr.2289704

36. Gurevich A, Saveliev V, Vyahhi N, Tesler G. QUAST: quality assessment tool for genome assemblies. Bioinformatics 2013;29:1072-1075 doi: 10.1093/bioinformatics/btt086

37. Kidsley AK, White RT, Beatson SA, Saputra S, Schembri MA, Gordon D, et al. Companion animals are spillover hosts of the multidrug-resistant human extraintestinal Escherichia coli pandemic clones ST131 and ST1193. Frontiers in Microbiology 2020;11:1968 doi: 10.3389/fmicb.2020.01968

38. Price LB, Johnson JR, Aziz M, Clabots C, Johnston B, Tchesnokova V, et al. The epidemic of extendedspectrum-beta-lactamase-producing Escherichia coli ST131 is driven by a single highly pathogenic subclone, H30-Rx. mBio 2013;4:e00377-13 doi: 10.1128/mBio.00377-13

39. Huang W, Li L, Myers JR, Marth GT. ART: a next-generation sequencing read simulator. Bioinformatics 2012;28:593-594 doi: 10.1093/bioinformatics/btr708

40. Li H, Durbin R. Fast and accurate short read alignment with Burrows-Wheeler transform. Bioinformatics 2009;25:1754-1760 doi: 10.1093/bioinformatics/btp324

41. Li H, Handsaker B, Wysoker A, Fennell T, Ruan J, Homer N, et al. The Sequence Alignment/Map format and SAMtools. Bioinformatics 2009;25:2078-2079 doi: 10.1093/bioinformatics/btp352

42. McKenna A, Hanna M, Banks E, Sivachenko A, Cibulskis K, Kernytsky A, et al. The Genome Analysis Toolkit: a MapReduce framework for analyzing next-generation DNA sequencing data. Genome Research 2010;20:1297-1303 doi: 10.1101/gr.107524.110

43. DePristo MA, Banks E, Poplin R, Garimella KV, Maguire JR, Hartl C, et al. A framework for variation discovery and genotyping using next-generation DNA sequencing data. Nature Genetics 2011;43:491-498 doi: 10.1038/ng.806

44. Quinlan AR, Hall IM. BEDTools: a flexible suite of utilities for comparing genomic features. Bioinformatics 2010;26:841-842 doi: 10.1093/bioinformatics/btq033

45. Cingolani P, Platts A, Wang le L, Coon M, Nguyen T, Wang L, et al. A program for annotating and predicting the effects of single nucleotide polymorphisms, SnpEff: SNPs in the genome of Drosophila melanogaster strain $\mathrm{w}^{1118}$; iso-2; iso-3. Fly 2012;6:80-92 doi: 10.4161/fly.19695

46. Sarovich DS, Price EP. SPANDx: a genomics pipeline for comparative analysis of large haploid whole genome re-sequencing datasets. BMC Research Notes 2014;7:618 doi: 10.1186/1756-0500-7-618 
medRxiv preprint doi: https://doi.org/10.1101/2021.05.21.21257487; this version posted May 24, 2021. The copyright holder for this preprint (which was not certified by peer review) is the author/funder, who has granted medRxiv a license to display the preprint in perpetuity. It is made available under a CC-BY-NC-ND 4.0 International license.

47. Stamatakis A. RAxML version 8: a tool for phylogenetic analysis and post-analysis of large phylogenies. Bioinformatics 2014;30:1312-1313 doi: 10.1093/bioinformatics/btu033

48. Zhang H, Gao S, Lercher MJ, Hu S, Chen WH. EvolView, an online tool for visualizing, annotating and managing phylogenetic trees. Nucleic Acids Research 2012;40:W569-W572 doi: 10.1093/nar/gks576

49. He Z, Zhang H, Gao S, Lercher MJ, Chen WH, Hu S. Evolview v2: an online visualization and management tool for customized and annotated phylogenetic trees. Nucleic Acids Research 2016;44:W236W241 doi: 10.1093/nar/gkw370

50. Rambaut A, Lam TT, Max Carvalho L, Pybus OG. Exploring the temporal structure of heterochronous sequences using TempEst (formerly Path-O-Gen). Virus Evolution 2016;2:vew007 doi: 10.1093/ve/vew007

51. Bouckaert R, Heled J, Kuhnert D, Vaughan T, Wu CH, Xie D, et al. BEAST 2: a software platform for Bayesian evolutionary analysis. PLOS Computational Biology 2014;10:e1003537 doi: /10.1371/journal.pcbi.1003537

52. Darriba D, Taboada GL, Doallo R, Posada D. jModelTest 2: more models, new heuristics and parallel computing. Nature Methods 2012;9:772 doi: 10.1038/nmeth.2109

53. Guindon S, Gascuel O. A simple, fast, and accurate algorithm to estimate large phylogenies by maximum likelihood. Systematic Biology 2003;52:696-704 doi: 10.1080/10635150390235520

54. Arnott JM, Morgan M. Escherichia coli bacteraemia in Wales, a case-series analysis. Poster presented at: Public Health England's Applied Epidemiology Scientific Conference. Coventry, United Kingdom; 2016.

55. Whitfield C. Biosynthesis and assembly of capsular polysaccharides in Escherichia coli. Annual Review of Biochemistry 2006;75:39-68 doi: 10.1146/annurev.biochem.75.103004.142545

56. Whitfield C, Roberts IS. Structure, assembly and regulation of expression of capsules in Escherichia coli. Molecular Microbiology 1999;31:1307-1319 doi: 10.1046/j.1365-2958.1999.01276.x

57. Sullivan MJ, Petty NK, Beatson SA. Easyfig: a genome comparison visualizer. Bioinformatics 2011;27:1009-1010 doi: 10.1093/bioinformatics/btr039

58. Jin DJ, Gross CA. Mapping and sequencing of mutations in the Escherichia coli rpoB gene that lead to rifampicin resistance. Journal of Molecular Biology 1988;202:45-58 doi: 10.1016/0022-2836(88)90517-7

59. Ludden C, Decano AG, Jamrozy D, Pickard D, Morris D, Parkhill J, et al. Genomic surveillance of Escherichia coli ST131 identifies local expansion and serial replacement of subclones. Microbial Genomics 2020;6 doi: 10.1099/mgen.0.000352

60. Holt KE, Thieu Nga TV, Thanh DP, Vinh H, Kim DW, Vu Tra MP, et al. Tracking the establishment of local endemic populations of an emergent enteric pathogen. Proceedings of the National Academy of Sciences of the United States of America 2013;110:17522-17527 doi: 10.1073/pnas.1308632110

61. Stoesser N, Sheppard AE, Pankhurst L, De Maio N, Moore CE, Sebra R, et al. Evolutionary history of the global emergence of the Escherichia coli epidemic clone ST131. mBio 2016;7:e02162 doi: 10.1128/mBio.02162-15

62. Findlay J, Gould VC, North P, Bowker KE, Williams MO, MacGowan AP, et al. Characterization of cefotaxime-resistant urinary Escherichia coli from primary care in South-West England 2017-18. Journal of Antimicrobial Chemotherapy 2020;75:65-71 doi: 10.1093/jac/dkz397

63. Cammarata A. The molecular basis of antibiotic action. By Gale EF, Cundliffe E, Reynolds PE, Richmond MH, and Waring MJ. New York, United States of America: Wiley; 1972 doi: 10.1002/jps.2600620955

64. Pongs O. Chloramphenicol. In: Hahn FE, editor. Antibiotics V - Mechanism of Action of Antibacterial Agents. New York, United States of America: Springer-Verlag; 1979. pp. 272-303.

65. Langmead B, Salzberg SL. Fast gapped-read alignment with Bowtie 2. Nature Methods 2012;9:357-359 doi: 10.1038/nmeth.1923

66. Rumble SM, Lacroute P, Dalca AV, Fiume M, Sidow A, Brudno M. SHRiMP: accurate mapping of short color-space reads. PLOS Computational Biology 2009;5:e1000386 doi: 10.1371/journal.pcbi.1000386

67. Garrison E, Marth G. Haplotype-based variant detection from short-read sequencing. arXiv:12073907v2 [Preprint]. 2012. Available from: https://arxiv.org/abs/1207.3907v2

68. Aziz A, Currie BJ, Mayo M, Sarovich DS, Price EP. Comparative genomics confirms a rare melioidosis human-to-human transmission event and reveals incorrect phylogenomic reconstruction due to polyclonality. Microbial Genomics 2020;6 doi: 10.1099/mgen.0.000326 